\title{
Effect of Chopped Basalt Fibers on the Mechanical Properties and Microstructure of High Performance Fiber Reinforced Concrete
}

\author{
Tehmina Ayub, Nasir Shafiq, and M. Fadhil Nuruddin \\ Civil Engineering Department, Universiti Teknologi PETRONAS, Bandar Seri Iskandar, 31750 Tronoh, Perak, Malaysia \\ Correspondence should be addressed to Tehmina Ayub; tehminaa@hotmail.com
}

Received 14 April 2014; Revised 30 June 2014; Accepted 2 July 2014; Published 13 October 2014

Academic Editor: Lian Gao

Copyright (C) 2014 Tehmina Ayub et al. This is an open access article distributed under the Creative Commons Attribution License, which permits unrestricted use, distribution, and reproduction in any medium, provided the original work is properly cited.

\begin{abstract}
This paper presents the mechanical properties and the microstructure of the high performance fiber reinforced concrete (HPFRC) containing up to $3 \%$ volume fraction of chopped Basalt fibers. Three types of the concrete were prepared, out of which, the first type was prepared by utilizing $100 \%$ cement content. The other two types of the concrete were prepared by replacing $10 \%$ cement content with silica fume and the locally produced metakaolin. Using each concrete type, four mixes were prepared in which Basalt fibers were added in the range of $0-3 \%$; that is, total twelve mixes of the HPFRC concrete were prepared. From each of the twelve concrete mixes, total twelve specimens were cast to determine the mechanical properties of the HPFRC including compressive strength (cube and cylinder), splitting tensile strength, and the flexural strength. In this way, a total of 108 specimens were cast and tested in this study. Test results showed that the addition of the Basalt fibers significantly increased the tensile splitting strength and the flexural strength of the HPFRC, while there was slight improvement in the compressive strength with the addition of Basalt fibers. The microstructure of HPFRC was examined to determine the interfacial transition zone (ITZ) between the aggregates and the paste by using field emission scanning electron microscope (FESEM), which showed the improvement of the ITZ due to the addition of the Basalt fibers.
\end{abstract}

\section{Introduction}

The mechanical properties of the concrete significantly depend on the microstructure, especially on the pore structure. The pore structure of the concrete can be improved by using mineral admixtures, which alongside improves the properties of the fresh concrete, [1], hardened concrete [2], and the durability of the concrete [3]. Among various mineral admixtures, silica fume is the most widely thoroughly investigated and a well-established mineral admixture. Silica fume was used in the construction of several Civil Engineering projects as an essential constituent of high strength concrete. However, high cost of the concrete produced by the use of silica fume and the shrinkage of the concrete are the two major concerns with the use of silica fume [4]. Recently, metakaolin has gained significant attention of researchers and several studies are reported in the literature about the mechanical properties of concrete containing metakaolin with and without using fibers [5-7].
In this paper, authors investigated the mechanical properties of the three types of high performance fiber reinforced concrete (HPFRC) containing chopped Basalt fibers. 100\% cement content was utilized in the first concrete type. However, in the second and the third concrete type, 10\% cement content was replaced with the silica fume and the locally produced metakaolin, respectively. The detail investigation of the production of locally produced metakaolin is given in [8]. Chopped Basalt fibers are relatively new in the market, which are recently used in several studies as microreinforcements for the concrete [9-12] and showed encouraging results. The first use of the Basalt fibers was reported in 1998 in a report published in USA for the Highway Innovations Deserving Exploratory Analysis (IDEA) Project 45 [13]. The results of the performances of Basalt fiber reinforced concrete were presented using maximum fiber volume as $0.5 \%$ and the prominent features endorsed to the Basalt fiber reinforced concrete were higher energy absorption capacity and the increased ductility. It was further added that the Basalt fibers 
easily dispersed within the concrete mix without causing segregation and that the fibers lose their shape due to the flexible structure. Similar conclusions are reported in $[14,15]$.

Basalt fiber is a high strength fiber with high elastic modulus, high thermal stability, chemical stability [16], good sound insulation, and electrical characteristics [17]. To date, the maximum fiber volume used to investigate the mechanical properties is $0.5 \%[13,18]$. This volume percentage is categorized as "Low volume fraction $(<1 \%)$ " which is usually used to reduce shrinkage cracking of the structural members such as slabs and pavements, due to large exposed surface [19]. For the structural application, higher volume fraction that is greater than $2 \%$ is recommended to obtain strainhardening behavior of the concrete. The use of 1 to $2 \%$ of the fiber volume may be beneficial in structural application where there is a requirement of high energy absorption capability, improved resistance against delamination, spalling and fatigue, modulus of rupture, impact resistance, and the fracture toughness of the concrete [19].

In this study, the information on the microstructure and the mechanical properties of the HPFRC containing 1 to $3 \%$ fiber volumes is provided due to research gap in the literature pertaining to the use of moderate to higher volume of Basalt fibers in concrete. In order to achieve this objective, an experimental investigation was carried out to observe the behavior of the HPFRC with a cylinder compressive strength in the range of 73 to $85 \mathrm{MPa}$ using $0-3 \%$ of Basalt fiber volume. Silica fume and locally produced metakaolin were used as partially cement replacing material to observe the effect on the strength increase. The mechanical properties determined in this study were compressive strength (both cube and cylinder), splitting tensile strength, and the flexural strength. Alongside, the empirical relationship between the fiber volume and the mechanical properties of the HPFRC was proposed.

\section{Experimental Program}

2.1. Materials. In this study, three different concrete mixes were prepared using $0,1,2$, and $3 \%$ Basalt fiber volume fractions measured with respect to the overall volume of the concrete. The first mix was prepared by using $100 \%$ cement and the other two mixes were prepared by replacing $10 \%$ cement content with the silica fume and the locally produced metakaolin. The physical and the chemical properties of ordinary Portland cement (OPC), silica fume, and metakaolin are given in Table 1. The chemical properties of silica fume show that the major chemical component of the silica fume is quartz, that is, $\mathrm{SiO}_{2}(91.40 \%)$, and it has specific gravity and BET specific surface area as 2.20 and $16.46 \mathrm{~m}^{2} / \mathrm{g}$, respectively. The X-ray diffraction (XRD) pattern shows that the silica fume contains mainly amorphous phase of silica with a small amount of crystallized quartz $\left(\mathrm{SiO}_{2}\right)$. The metakaolin was locally produced and its calcination detail is given in [8]. The physical and chemical properties of metakaolin show that the metakaolin contains $53.87 \%$ of $\mathrm{SiO}_{2}$ and $38.57 \%$ of $\mathrm{Al}_{2} \mathrm{O}_{3}$ with an $11 \%$ loss on ignition. The metakaolin has
TABLE 1: Physical and chemical composition of OPC, silica fume, and metakaolin.

\begin{tabular}{lccc}
\hline Properties & OPC & Silica fume & Metakaolin \\
\hline Specific gravity & 3.05 & 2.2 & - \\
BET surface area $\left(\mathrm{m}^{2} / \mathrm{g}\right)$ & 0.39 & 16.46 & 12.17 \\
Loss on ignition $(\%)$ & - & 2.0 & 1.85 \\
Average particle size $(\mu \mathrm{m})$ & - & - & $2.5-4.5$ \\
$\mathrm{SiO}_{2}(\%)$ & 20.44 & 91.40 & 53.87 \\
$\mathrm{Al}_{2} \mathrm{O}_{3}(\%)$ & 2.84 & 0.09 & 38.57 \\
$\mathrm{CaO}(\%)$ & 67.73 & 0.93 & 0.04 \\
$\mathrm{MgO} \%)$ & 1.43 & 0.78 & 0.96 \\
$\mathrm{SO}_{3}(\%)$ & 2.20 & - & - \\
$\mathrm{Na}_{2} \mathrm{O}(\%)$ & 0.02 & 0.39 & 0.04 \\
$\mathrm{~K}_{2} \mathrm{O}(\%)$ & 0.26 & 2.41 & 2.68 \\
$\mathrm{TiO}_{2}(\%)$ & 0.17 & - & - \\
$\mathrm{MnO}(\%)$ & 0.16 & 0.05 & 0.01 \\
$\mathrm{Fe}_{2} \mathrm{O}_{3}(\%)$ & 4.64 & - & 1.40 \\
$\mathrm{TiO}_{2}(\%)$ & - & 0.04 & 0.95 \\
$\mathrm{P}_{2} \mathrm{O}_{5}(\%)$ & - & 0.38 & 0.10 \\
\hline
\end{tabular}

Note: properties were determined by $\mathrm{X}$-ray fluorescence $(\mathrm{XRF})$ and Brunauer-Emmett-Teller (BET) specific surface area analysis.

$12.17 \mathrm{~m}^{2} / \mathrm{g}$ specific surface area determined by the BrunauerEmmett-Teller (BET) specific surface area analysis, which is $26 \%$ smaller than that of the surface area of silica fume. The X-ray diffraction (XRD) patterns of the silica fume and the metakaolin are shown in Figure 1, whereas field emission scanning electron microscope (FESEM) imaging of the silica fume and the metakaolin at 50X and 5.00 KX magnifications is shown in Figures 2 and 3, respectively, for the identification of the particle size distributions. It can be seen that metakaolin has more even particle size distribution as compared to the silica fume. At a magnification of 5.00 $\mathrm{KX}$, it can be visualized that metakaolin is an alumina-silicate mineral with well-formed six-sided flakes.

For all the concrete mixes, two sizes of the coarse aggregates, ranging from 20 to $10 \mathrm{~mm}$ and smaller than $10 \mathrm{~mm}$, were used. River sand with fineness modulus of 3.55 was used as fine aggregate. 1, 2, and 3\% of chopped Basalt fibers (measured with respect to the total volume of the concrete) were used as microreinforcement. The properties and the chemical composition of chopped Basalt fibers chopped strands are given in the Tables 2 and 3. In order to improve the workability and the fresh properties of HPFRC, Sika ViscoCrete-1600 was used as superplasticizer. This superplasticizer is specially designed to produce high workable concrete and mortar and meets the requirements of ASTM C494-86 Type G and BS 5075: Part 3 standards.

2.2. Concrete Composition, Mixing, and Casting Detail. The material composition, quantities, and the nomenclature proposed for each mix are given in Table 4. All materials were mixed in $0.05 \mathrm{~m}^{3}$ capacity pan mixer that is recommended as 


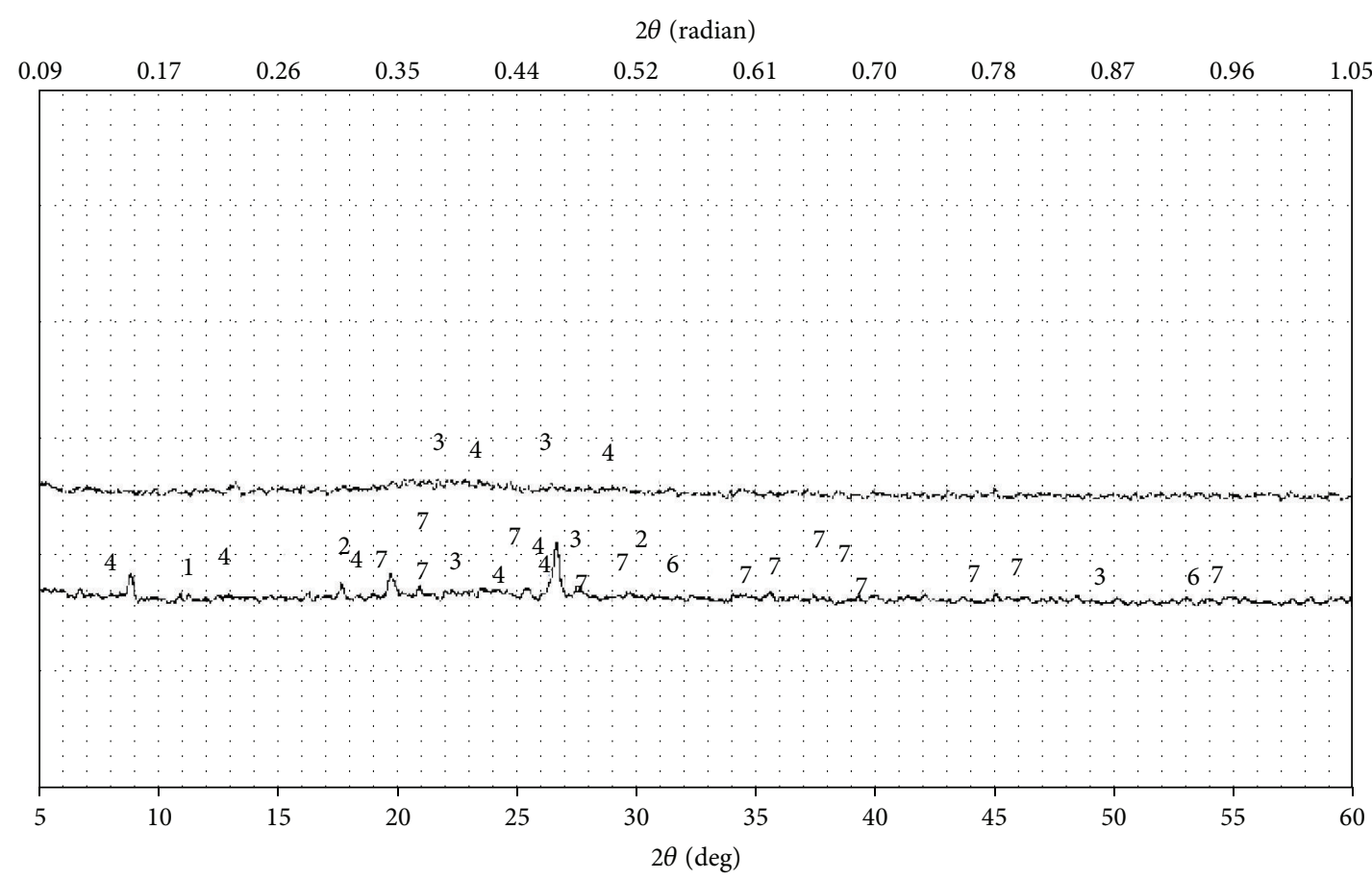
_- Microsilica
(2) Alunite
(5) Bementite
(8) Mullite
- - - Metakaolin
(3) Quartz
(6) Cristobalite
(1) Kaolinite/dickite
(4) $\mathrm{SiO}_{2}$
(7) Di-Alumino silicate

FIGURE 1: X-ray diffraction (XRD) spectrum of the silica fume and metakaolin.

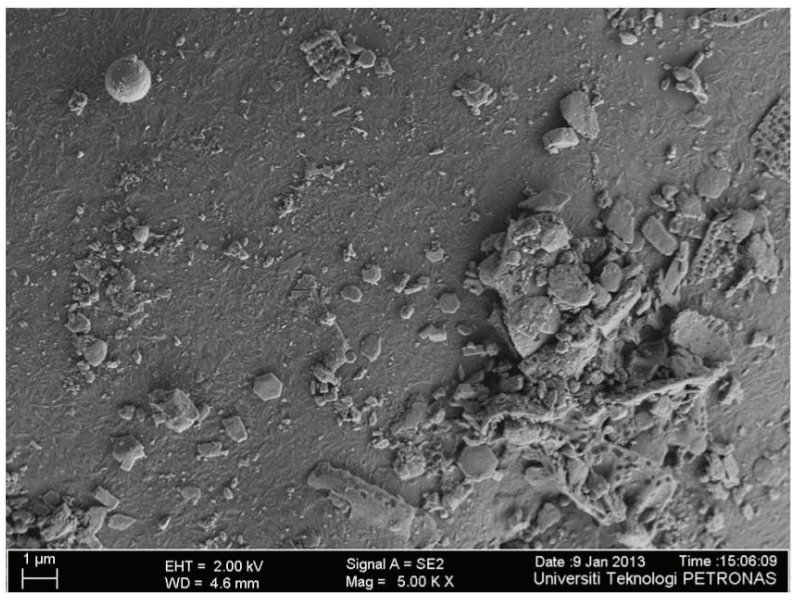

(a)

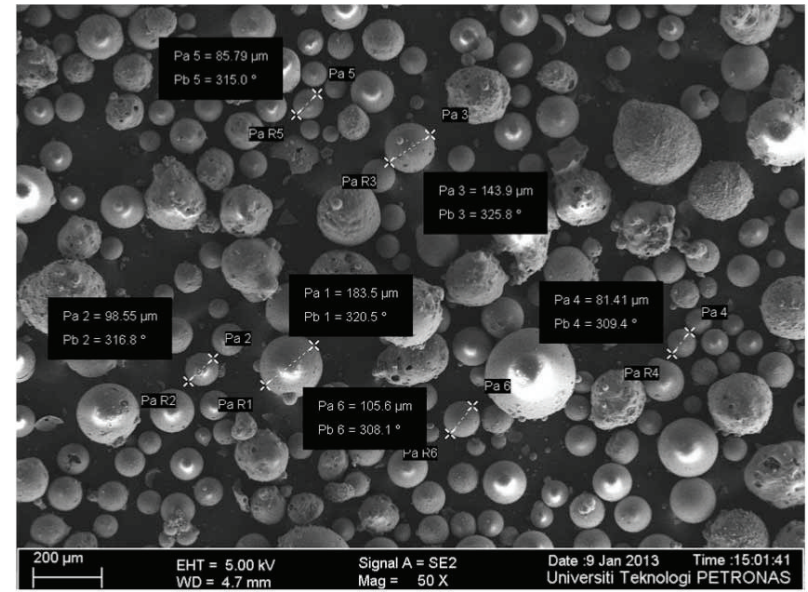

(b)

FIGURE 2: Microstructure of silica fume through field emission scanning electron microscope (FESEM).

the BS 1881-125: 1986 standard. For the concrete mixes with fibers, extra time was consumed to ensure the proper mixing. During mixing, no fiber balls and no segregation were observed in concrete mixes and all constituents mutually behaved as a unified mass due to the microsize and the flexible nature of the chopped Basalt fibers.

From each of the twelve mixes (Refer Table 4), total of six cylinders (size: $100 \times 200 \mathrm{~mm}$ as per BS 1881-110: 1983 standard), three cubes (size: $100 \times 100 \times 100 \mathrm{~mm}$ as per BS 1881-108: 1983 standard), and three beams (size: 100 $\times 100 \times 500 \mathrm{~mm}$ as per BS 1881-118: 1983 standard) were cast. A total of 108 specimens were tests in this study. All molds of the specimens were fully poured with the concrete except cylinders where $3-6 \mathrm{~mm}$ depth from the top was left partially unfilled to provide mortar capping. This space was then filled with mortar, which was prepared by using cement and water cement ratio similar to that used in the concrete. The procedure of capping followed standard procedure recommended by BS 1881-110: 1983. After 24 hours, all specimens were put in water curing tank subsequently 


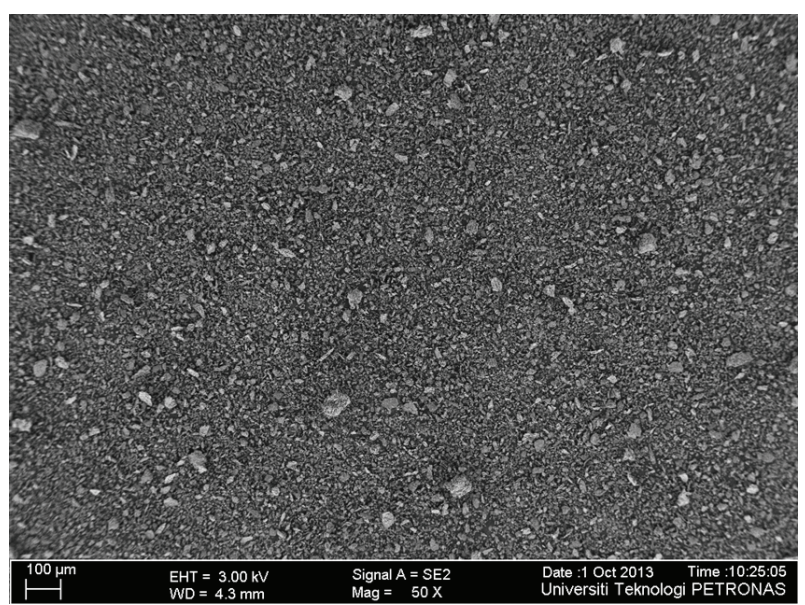

(a)

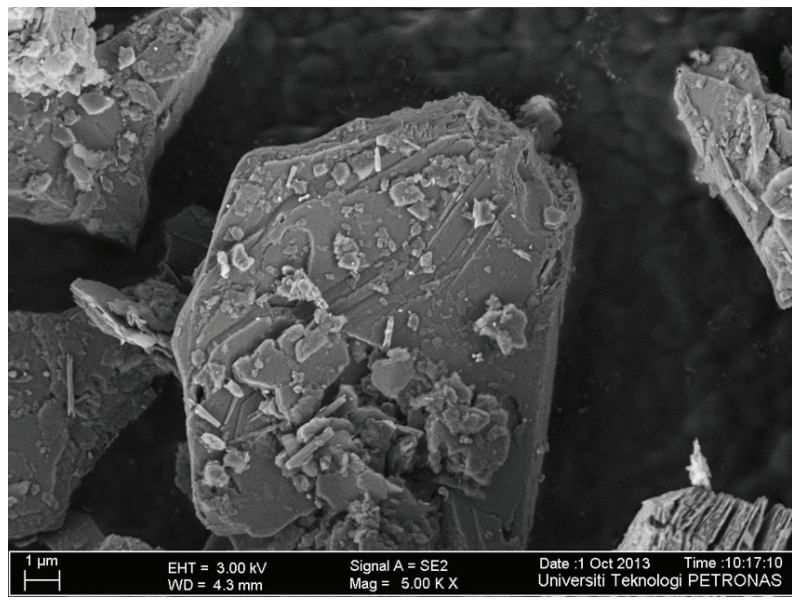

(b)

FIGURE 3: Microstructure of metakaolin through field emission scanning electron microscope (FESEM).

removing from their molds for 28 days as recommended in BS 1881-111: 1983 standard. After the completion of the curing period, all specimens were taken out of the tank and were left to dry for few hours before testing as per BS 1881-111: 1983 standard.

2.3. Testing Detail. Special attention was paid before and during testing of the specimens. Before testing, calibration of the machines was checked and the bearing surfaces of testing machines were wiped clean and there were no loose grits or other extraneous materials on the surface, which may be in contact with the specimens.

The compressive strength of the cubes was determined according to the BS 1881 Part 116: 1983 standard using a compression testing machine of $3000 \mathrm{kN}$ capacity. The compression test was performed at $3 \mathrm{kN} / \mathrm{sec}$ loading rate. No strain gages were applied to the cube surfaces to obtain the strain data.

The testing of three cylinders for the compressive behavior was performed in accordance with ASTM C 39/C 39 M: 2005 standard. Strain measurements were recorded using
TABle 2: Properties of Basalt fibers.

\begin{tabular}{lc}
\hline Fiber details & Basalt fibers \\
\hline Fiber type & Filament type \\
Diameter $(\mu \mathrm{m})$ & 18 \\
Cut length $(\mathrm{mm})$ & 25 \\
Tensile strength $(\mathrm{MPa})$ & $4100-4840$ \\
Elastic modulus $(\mathrm{GPa})$ & $93.1-110$ \\
Specific gravity & $2.63-2.8$ \\
Elongation $(\%)$ & 3.1 \\
\hline
\end{tabular}

Note: these properties were provided by the manufacturer.

linear variable differential transformer (LVDT). The compression test of the cylinders was performed under deformation control condition at the loading rate of $0.0083 \mathrm{~mm} / \mathrm{sec}$.

The tensile splitting strength of the cylinders was determined according to the BS 1881 Part 117: 1983 standard using the same machine as used for the compression test of the cubes. The test was performed at $0.3 \mathrm{kN} / \mathrm{sec}$ constant loading rate.

The flexural strength of the beams was determined according to the BS 1881 Part 118: 1983 standard. The test was performed at $0.05 \mathrm{kN} / \mathrm{sec}$ loading rate.

\section{Test Results and Discussion}

3.1. Compressive Behavior. The compression test results of the cubes and the cylinders are presented in Table 5. The stressstrain curves of the cylinders are presented in Figure 4. There are several researchers who thoroughly discussed the stressstrain behavior of the concrete. For example, Oztekin et al. [20] and Wee et al. [21] mentioned that the shape of the stressstrain curves is very sensitive to the testing conditions such as size and shape of the specimen, specimen verses machine stiffness, machine's self-stiffness, loading type, strain rate, and type and length of strain gauge. Therefore, one valid stressstrain curve for the concrete is impossible.

The stress-strain curves shown in Figure 4 indicate that the slope of ascending branch of all the mixes is more linear as compared to the descending branch. The slope of the descending branch of the stress-strain curve of the control mix is steeper than those curves of the mixes in which Basalt fibers were added. The values of the strains of the control mixes were found to be the lowest among all the mixes. This indicates that Basalt fibers were fully active and showed resistance against extensive cracking and the dilation of concrete. With the increasing fiber volume, the resistance against cracking was also increased; therefore, specimens attained slightly higher load. At any strain level in the descending branch, specimens containing 3\% volume of the Basalt fibers showed higher stress values, followed by the specimens containing $2 \%$ and $1 \%$ volume of the Basalt fibers.

The effects of Basalt fiber volume on the results of the compressive strength of all mixes of HPFRC are shown in Figure 5. It can be seen that the results of cube and cylinder compressive strength of the concrete in which silica fume and 
TABLE 3: Chemical composition of Basalt fibers chopped strands.

\begin{tabular}{lcccccrr}
\hline & \multicolumn{2}{c}{ Chemical composition of Basalt fiber (\%) } \\
$\mathrm{SiO}_{2}$ & $\mathrm{Al}_{2} \mathrm{O}_{3}$ & $\mathrm{CaO}$ & $\mathrm{MgO}$ & $\mathrm{FeO}+\mathrm{Fe}_{2} \mathrm{O}_{3}$ & $\mathrm{TiO}_{2}$ & $\mathrm{Na}_{2} \mathrm{O}+\mathrm{K}_{2} \mathrm{O}$ & $\mathrm{O}$ thers \\
\hline $51.6-59.3$ & $14.6-18.3$ & $5.9-9.4$ & $3.0-5.3$ & $9.0-14.0$ & $0.8-2.25$ & $0.8-2.25$ & $0.09-0.13$ \\
\hline
\end{tabular}

Note: chemical composition of Basalt fiber is provided by the supplier.

TABLE 4: Mixture proportion of the HPFRC mixes.

\begin{tabular}{|c|c|c|c|c|c|c|c|c|c|}
\hline \multirow{3}{*}{$\begin{array}{l}\text { Concrete } \\
\text { type }\end{array}$} & \multirow[b]{3}{*}{ Cement } & \multicolumn{4}{|c|}{ Mix ingredients $\left(\mathrm{kg} / \mathrm{m}^{3}\right)$} & \multirow[b]{3}{*}{ Water } & \multirow{3}{*}{$\begin{array}{l}\text { Basalt fiber } \\
(\%)^{*}\end{array}$} & \multirow{3}{*}{$\begin{array}{l}\text { Specimen } \\
\text { label }\end{array}$} & \multirow{3}{*}{$\begin{array}{l}\text { High range water } \\
\text { reducing admixture } \\
\text { (superplasticizer) }\end{array}$} \\
\hline & & & Fine & Coarse aq & gregate (CA) & & & & \\
\hline & & admixture & $\begin{array}{l}\text { aggregate } \\
\text { (FA) }\end{array}$ & $<10 \mathrm{~mm}$ & $\begin{array}{l}10 \text { to } \\
20 \mathrm{~mm}\end{array}$ & & & & \\
\hline \multirow{4}{*}{$\begin{array}{l}\text { Palin } \\
\text { concrete }\end{array}$} & \multirow{4}{*}{450} & \multirow{4}{*}{0} & \multirow{12}{*}{670} & \multirow{12}{*}{500} & \multirow{12}{*}{600} & \multirow{12}{*}{$\begin{array}{c}180 \\
(w / c=0.4)\end{array}$} & $\mathbf{0}$ & P-0 & \multirow{12}{*}{$\begin{array}{l}\text { Variable, target } \\
\text { slump } \\
75 \pm 10 \mathrm{~mm}\end{array}$} \\
\hline & & & & & & & 1 & PB-1 ${ }^{*}$ & \\
\hline & & & & & & & 2 & PB-2 & \\
\hline & & & & & & & 3 & PB-3 & \\
\hline \multirow{4}{*}{$\begin{array}{l}\text { Silica fume } \\
\text { concrete }\end{array}$} & \multirow{4}{*}{405} & \multirow{4}{*}{$\begin{array}{c}45 \\
\text { (silica fume) }\end{array}$} & & & & & $\mathbf{0}$ & S-0 & \\
\hline & & & & & & & 1 & SB-1 & \\
\hline & & & & & & & 2 & SB-2 & \\
\hline & & & & & & & 3 & SB-3 & \\
\hline \multirow{4}{*}{$\begin{array}{l}\text { Metakaolin } \\
\text { concrete }\end{array}$} & \multirow{4}{*}{405} & \multirow{4}{*}{$\begin{array}{c}45 \\
\text { (metakaolin) }\end{array}$} & & & & & $\mathbf{0}$ & P-0 & \\
\hline & & & & & & & 1 & MB-1 & \\
\hline & & & & & & & 2 & MB-2 & \\
\hline & & & & & & & 3 & MB-3 & \\
\hline
\end{tabular}

*Term "P" represents "Plain" concrete that is prepared by using $100 \%$ cement and " $\mathrm{B}$ " represents Basalt fiber, whereas number "1" after hyphen represents $1 \%$ fiber volume of the Basalt fibers.

Note: $1 \mathrm{~mm}=0.03937 \mathrm{in}$. and $1 \mathrm{~kg} / \mathrm{m}^{3}=0.06243 \mathrm{lb} / \mathrm{ft}^{3}$.

metakaolin were added as $10 \%$ replacement of cement are close to one another for all Basalt fiber volumes. Therefore, it can be inferred that the metakaolin can be used as an alternative of the silica fume without affecting the compressive strength. However, the improvement in the strain capacity of the concrete containing metakaolin is better than the concrete in which silica fume was added. Considering the results of average compressive strength of the cubes and the cylinders shown to be presented in Table 5, it was found that the addition of mineral admixtures increased the compressive strength of concrete. The increase in the cylinder and the cube strength was found to be as high as $15.37 \%$ and $9.85 \%$ compared to the plain concrete when silica fume was used; however, the addition of metakaolin increased the cube and cylinder compressive strength as $14.13 \%$ and $14.83 \%$.

The variation in the average cube and cylinder strengths of HPFRC containing Basalt fibers was found to be in the range of $\pm 4 \%$ compared to the average compressive strength of the control specimens. This shows that the addition of 1 to $3 \%$ Basalt fiber volume did not increase the compressive strength significantly. Similar results are recently reported by Jiang et al. [18]. On the other side, in comparison to the control, the average increase in the compressive strains was found to be $4.76 \%, 9.99 \%$, and $12.20 \%$ compared to the control, when Basalt fibers were added in the concrete mixes as $1 \%, 2 \%$, and $3 \%$ by volume, respectively.
According to Wee at al. [21], concrete attaining higher strength usually exhibits a higher strain value. Similar results were also obtained in this study. The results of the strains corresponding to the peak stress and the splitting tensile strength were significantly encouraging with the increase in the volume of the Basalt fibers. The effects of the increasing volume of the Basalt fibers on the compressive strains are shown in Figure 6.

3.2. Tensile Splitting Behavior. The results of the tensile splitting strength are presented in Table 5 , which show that the tensile splitting strength of the concrete increased with the addition of mineral admixture and fibers. In the plain concrete without fibers, the use of silica fume (S-0) and metakaolin (M-0) as $10 \%$ replacement of cement increased the tensile splitting strength of the concrete as $28.88 \%$ and $2.13 \%$ compared to the plain concrete ( $\mathrm{P}-0)$.

Within groups, the splitting tensile strength of the concrete with Basalt fibers was found to be higher than the concrete without fibers (i.e., control mix). In plain concrete, the increase in the tensile splitting strength was found to be $0 \%, 4.65 \%$, and $16.28 \%$ when Basalt fibers were added as 1,2 , and $3 \%$, respectively (i.e., specimens $\mathrm{PB}-1, \mathrm{~PB}-2$, and $\mathrm{PB}-3$ ). In silica fume concrete, the increase in the tensile splitting strength was found to be $0.09 \%, 1.05 \%$, and $20.15 \%$ when Basalt fibers were added as 1,2 , and $3 \%$, respectively (i.e., 


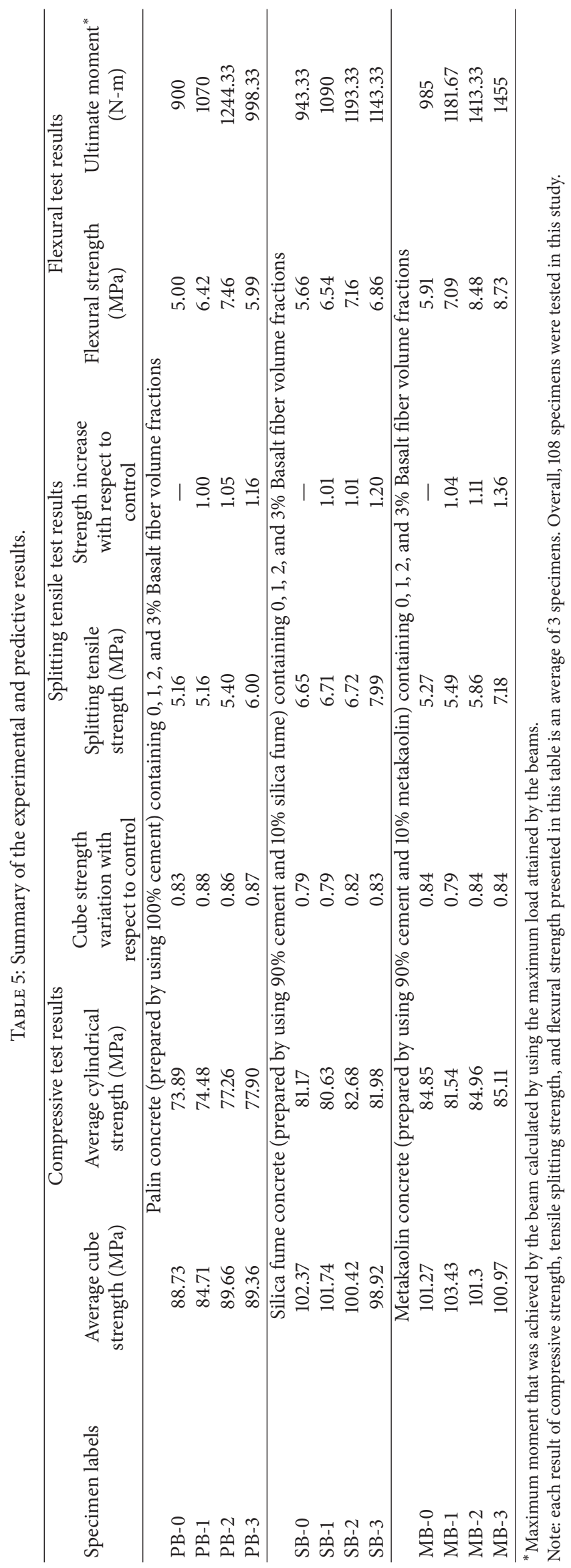




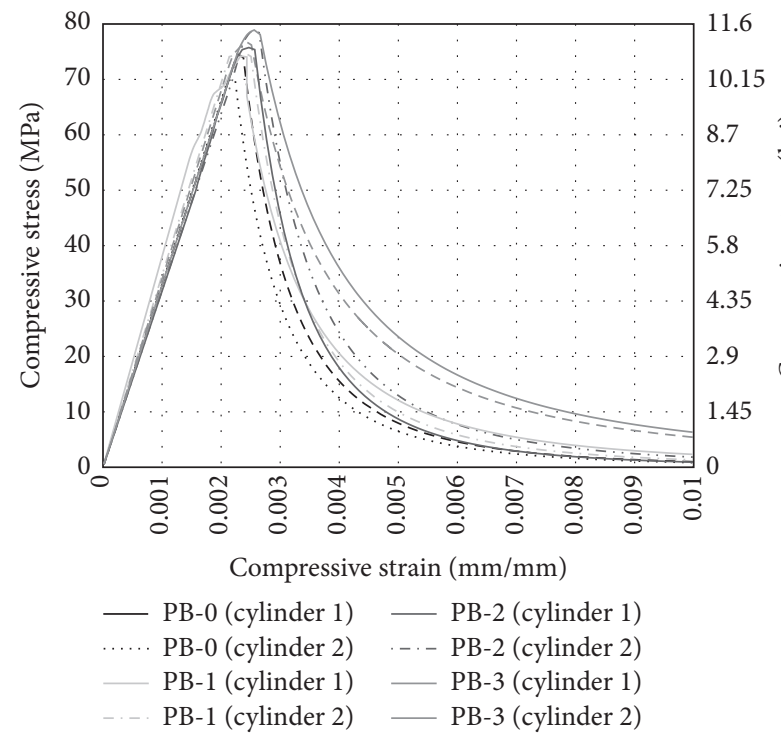

(a) Cylindrical stress versus strain behaviour of plain concrete

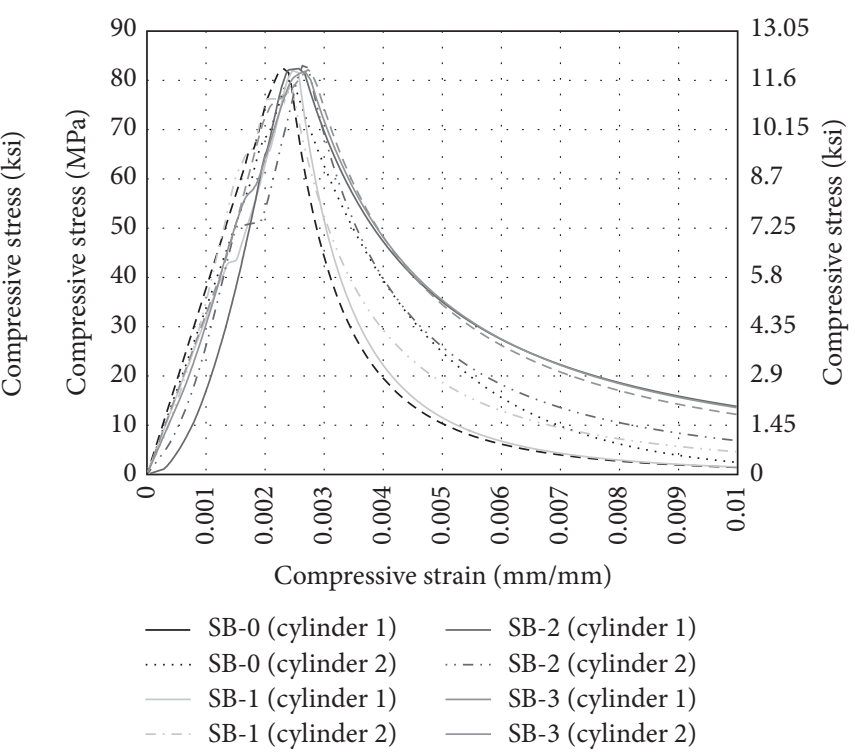

(b) Cylindrical stress versus strain behaviour of silica fume concrete
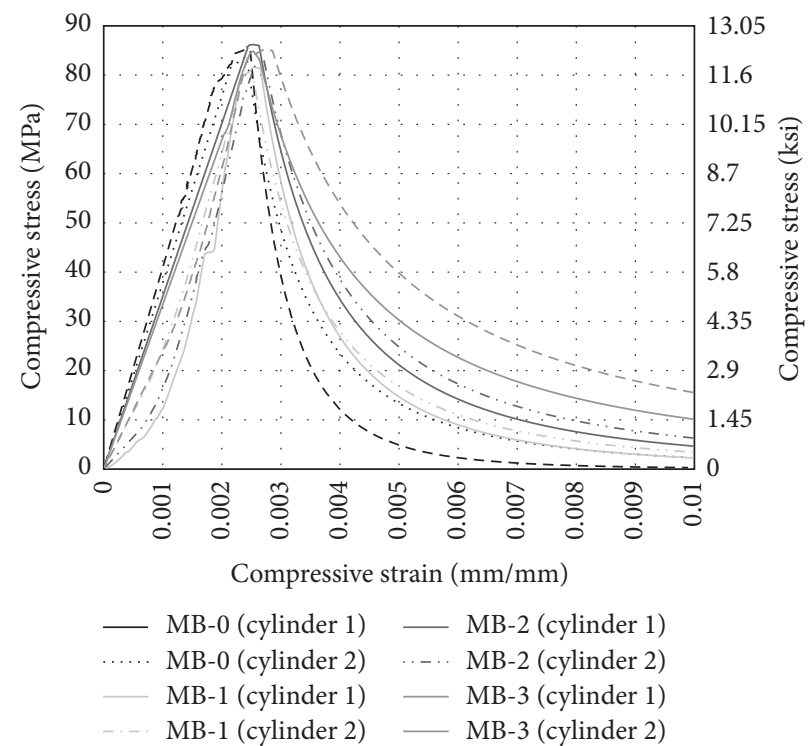

(c) Cylindrical stress versus strain behaviour of metakaolin concrete

FIgURE 4: Cylindrical compressive strength versus strain curves.

specimens SB-1, SB-2, and SB-3). Similarly, in metakaolin concrete, the increase in the tensile splitting strength was found to be $4.17 \%, 11.19 \%$, and $36.24 \%$ when Basalt fibers were added as 1, 2, and 3\%, respectively (i.e., specimens MB-1, MB2 , and MB-3). This shows that with the use of Basalt fibers, the tensile splitting strength increased and the highest results were obtained with the use of $3 \%$ fiber volume in all three mixes of HPFRC concrete (refer to Figure 7). However, the use of metakaolin is more effective in increasing the tensile splitting strength of the concrete, which can remarkably increase the tensile splitting strength of concrete up to $36.24 \%$ together with 3\% Basalt fiber volume.

The comparison of tensile splitting strength across the group shows that the highest tensile splitting strength was obtained with the silica fume concrete at the similar fiber volume. The increase in the tensile splitting strength of the silica fume concrete (i.e., series "S") was found to be $28.88 \%$, $30.04 \%, 24.44 \%$, and $33.17 \%$ higher than that of the plain concrete (i.e., series "P") when Basalt fibers were added as 0 , 1,2 , and $3 \%$, respectively. Similarly, the increase in the tensile splitting strength of the silica fume concrete (i.e., series "S") was found to be $26.19 \%, 22.22 \%, 14.68 \%$, and $11.28 \%$ higher than that of the metakaolin concrete (i.e., series " $M$ ") when Basalt fibers were added as $0,1,2$, and $3 \%$, respectively. The increase in the tensile splitting strength of the metakaolin concrete (i.e., series " $M$ ") was found to be $2.13 \%, 6.39 \%$, $8.52 \%$, and $19.66 \%$ higher than the plain concrete (i.e., series "P") when Basalt fibers were added as $0,1,2$, and $3 \%$, respectively. 


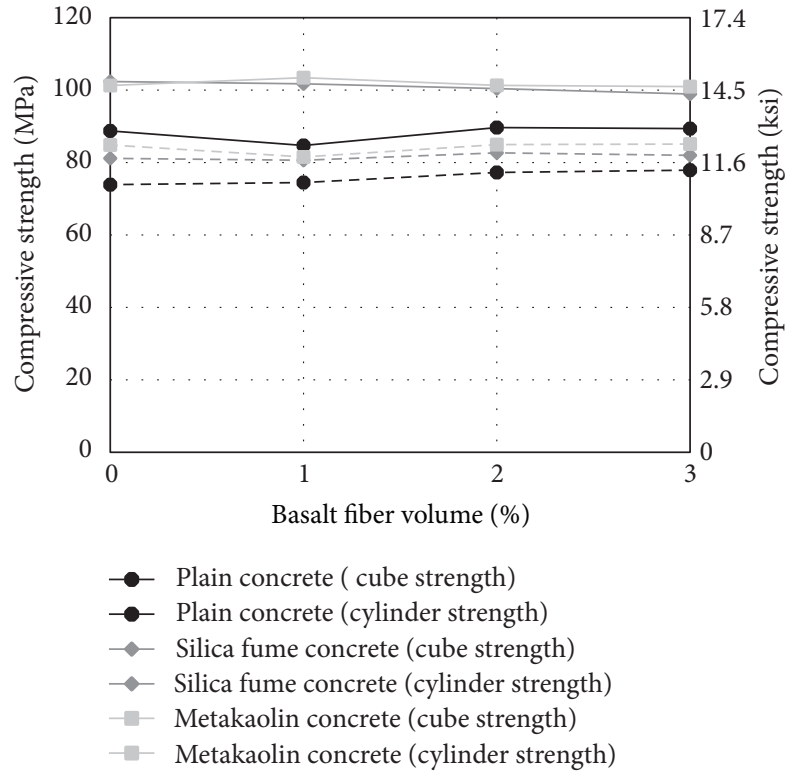

FIGURE 5: Average cube and cylinder compressive strength.

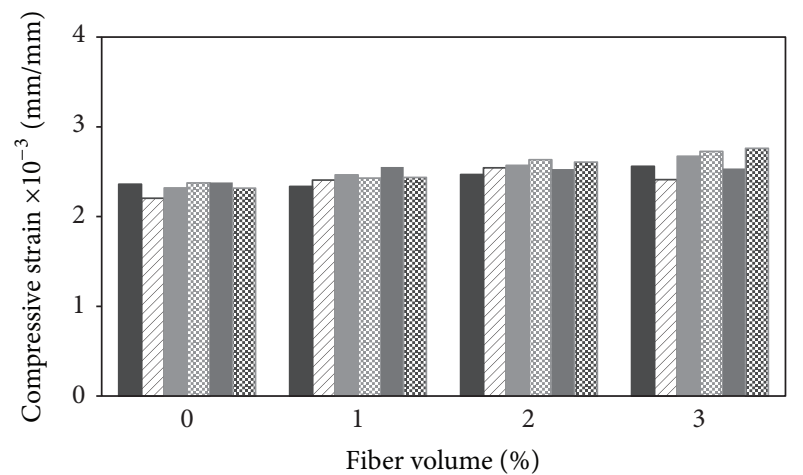

Plain concrete (cylinder 1)

Silica fume concrete (cylinder 1)

- Metakaolin concrete (cylinder 1)

Plain concrete (cylinder 2)

Silica fume concrete (cylinder 2)

Metakaolin concrete (cylinder 2)

FIGURE 6: Effect of the Basalt fibers on the compressive strains of HPFRC.

Upon averaging out the results of all series based on the similar fiber volume, it was found that the average increase in the tensile strength by using 1,2 , and $3 \%$ was $1.64 \%$, $5.27 \%$, and $23.95 \%$ higher than the control specimen (without fibers). The average increase in the tensile splitting strength of the concrete containing $2 \%$ and $3 \%$ of Basalt fibers was $3.57 \%$ and $21.95 \%$ higher than that of the concrete containing $1 \%$ Basalt fibers. The average increase in the tensile strength of the concrete in which 3\% Basalt fiber volume was added was $17.74 \%$ higher than those containing $2 \%$ Basalt fibers. Recently, Jiang et al. [18] reported the increase in the splitting tensile strength in the range of 14.08 to $24.34 \%$ by using

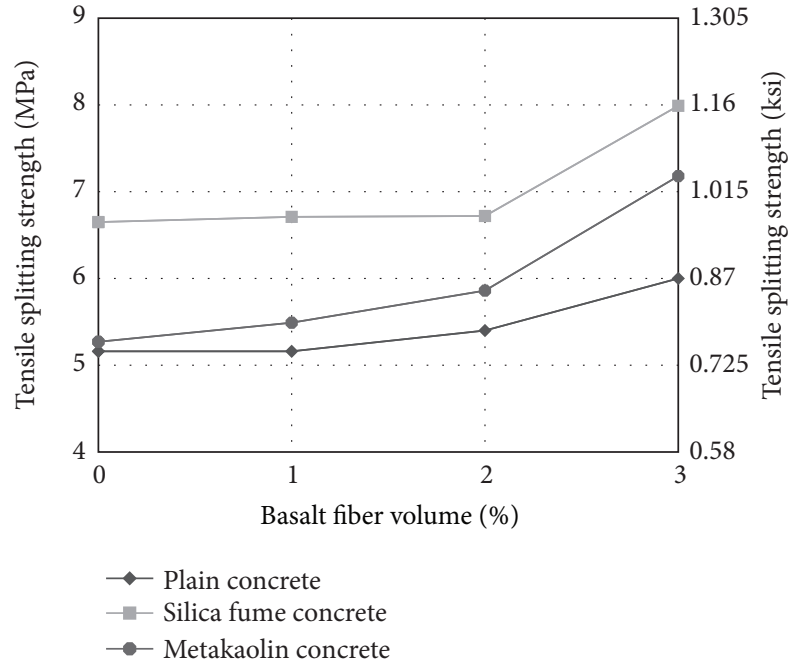

FIGURE 7: Variation in the splitting tensile strength.

$12 \mathrm{~mm}$ long Basalt fiber up to $0.5 \%$ fiber volume. In this study, the increase in the splitting tensile strength was also found using $25 \mathrm{~mm}$ long chopped Basalt fibers up to 3\% fiber volume. The highest increase in the average tensile splitting strength was found to be $24.22 \%$ with $3 \%$ basalt fiber volume. This confirms the conclusion reported by Jiang et al. [18] that the addition of Basalt fibers increases the tensile splitting strength of the concrete.

The dependence of splitting tensile strength on the compressive strength $\left(\sqrt{f_{c}^{\prime}}\right)$ is well known. Therefore, the following relationships between the average splitting tensile strength $\left(f_{\mathrm{sp}}\right)$ and the average cylinder compressive strength $\left(\sqrt{f_{c}^{\prime}}\right)$ were obtained:

$$
\begin{aligned}
& f_{\mathrm{sp}}=0.64 \sqrt{f_{c}^{\prime}} \quad \text { (for 0\% Basalt fiber) } \\
& f_{\mathrm{sp}}=0.65 \sqrt{f_{c}^{\prime}} \quad \text { (for 1\% Basalt fibers) } \\
& f_{\mathrm{sp}}=0.66 \sqrt{f_{c}^{\prime}} \quad \text { (for 2\% Basalt fibers) } \\
& f_{\mathrm{sp}}=0.78 \sqrt{f_{c}^{\prime}} \quad \text { (for 3\% Basalt fibers) }
\end{aligned}
$$

These expressions indicate that to obtain higher tensile strength, a higher fiber volume $(\geq 3 \%)$ should be used.

3.3. Flexural Behavior. The flexural strength development of HPFRC using Basalt fibers is shown in Figure 8. From the test results reported in Table 5, it was observed that in silica fume concrete without fibers, the flexural strength of the concrete was increased up to $13.2 \%$, whereas in metakaolin concrete, the flexural strength was increased up to $18.2 \%$ as compared to the plain concrete.

Within groups, the flexural strength of the concrete with Basalt fibers was found to be higher than the concrete without 


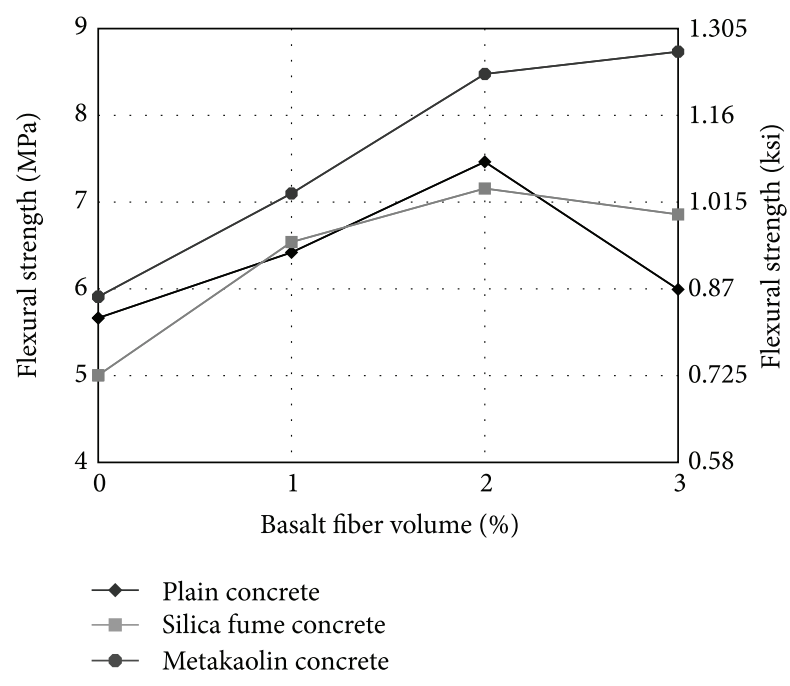

FIGURE 8: Variation in the flexural strength.

fibers (i.e., control mix). In plain concrete (i.e., series "P"), the increase in the flexural strength was found to be $18.89 \%$, $38.15 \%$, and $10.93 \%$ when Basalt fibers were added as 1, 2, and $3 \%$, respectively. In silica fume concrete (i.e., series "S"), the increase in the flexural strength was found to be $15.55 \%$, $26.50 \%$, and $21.20 \%$ when Basalt fibers were added as 1,2 , and $3 \%$, respectively. Similarly, in metakaolin concrete (i.e., series "M"), the increase in the tensile splitting strength was found to be $19.97 \%, 43.49 \%$, and $47.72 \%$ when Basalt fibers were added as 1,2 , and $3 \%$, respectively. From this, it can be inferred that the use of Basalt fiber is beneficial for the improvement of the flexural strength; however, the combination of metakaolin and 3\% Basalt fiber (i.e., specimen "MB-3") can increase the flexural strength up to 47.72 , which is considerably higher than the plain concrete (i.e., series "P") and silica fume concrete (i.e., series "S"). In plain and silica fume concrete, the highest flexural strength was achieved with $2 \%$ Basalt fibers (i.e., specimen "PB-2" and specimen "SB-2"). The decrease in the flexural strength using 3\% Basalt fiber (i.e., specimen "PB-3" and specimen "SB-3") was observed to be $19.71 \%$ and $4.19 \%$ compared to the plain concrete and silica fume concrete containing $2 \%$ Basalt fibers. The decrease in the flexural strength of the silica fume concrete containing 3\% (i.e., specimen "SB-3") was not significant compared to the plain concrete (i.e., specimen "PB-3"). The reason for the decrease in flexural strength at 3\% fiber volume may be due to the reasons that with increasing fiber volume, the water demand increases. However in this study, a constant water/(cement or binder) ratio of 0.4 is used, which might affect the quality of the concrete (though no balling effect was observed). It is already reported in the literature that use of silica fume increases the water demand, while use of metakaolin has no or very little effect on the water demand and has better workability of the concrete, and maintained the finishing even at 3\% Basalt fiber volume. At this stage, no conclusion can be drawn for the concrete containing 3\% Basalt fibers and further investigation is recommended prior to conclude any result.

Overall, the use of $1 \%, 2 \%$, and $3 \%$ Basalt fibers increased the average flexural strength of the concrete (i.e., plain concrete and the concrete in which silica fume and metakaolin were used) as $18.15 \%, 36.12 \%$, and $27.17 \%$ higher than that of the concrete without fibers. Recently, Jiang et al. [18] reported that the addition of $12 \mathrm{~mm}$ long Basalt fibers up to $0.5 \%$ increased the flexural strength of the concrete $7.35-$ $10.37 \%$ after 28 days. Based on the results of flexural strength obtained in this study, it can be confirmed that up to $2 \%$ Basalt fibers, the increase in the flexural strength can be achieved up to $36.12 \%$. The reason for the increase in the flexural strength, beside higher fiber volume, might be due to the use of dimension of the fiber used in this study.

Across the group, as already mentioned in the beginning of this section, an increase in the flexural strength was observed when silica fume and metakaolin were used as cement replacing material (i.e., series " $S$ " and series " $M$ "). The increases in the flexural strength results of the silica fume concrete (i.e., series "S") were found to be higher as $4.81 \%$ (with respect to $0 \%$ Basalt fiber volume), 1.87\% (with respect to $1 \%$ Basalt fiber volume), and $14.52 \%$ (with respect to $3 \%$ Basalt fiber volume). Similarly, in metakaolin concrete (i.e., series " $M$ "), the increases in the flexural strength were found to be higher as $9.44 \%$ (with respect to $0 \%$ Basalt fiber volume), $10.44 \%$ (with respect to $1 \%$ Basalt fiber volume), $13.67 \%$ (with respect to $1 \%$ Basalt fiber volume), and $45.74 \%$ (with respect to $3 \%$ Basalt fiber volume).

The following relationship between the average splitting tensile strength and average cylinder compressive strength was found:

$$
\begin{array}{r}
f_{\mathrm{fl}}=0.622 \sqrt{f_{c}^{\prime}} \text { or } f_{\mathrm{fl}}=0.971 f_{\mathrm{sp}} \\
(\text { for } 0 \% \text { Basalt fiber }), \\
f_{\mathrm{fl}}=0.753 \sqrt{f_{c}^{\prime}} \text { or } f_{\mathrm{fl}}=1.156 f_{\mathrm{sp}}
\end{array}
$$

(for $1 \%$ Basalt fibers),

$$
f_{\mathrm{fl}}=0.867 \sqrt{f_{c}^{\prime}} \quad \text { or } \quad f_{\mathrm{fl}}=1.285 f_{\mathrm{sp}}
$$

(for 2\% Basalt fibers),

$$
f_{\mathrm{fl}}=0.81 \sqrt{f_{c}^{\prime}} \text { or } f_{\mathrm{fl}}=1.0196 f_{\mathrm{sp}}
$$

(for 3\% Basalt fibers).

3.4. Microstructure of HPFRC. The microstructure of HPFRC with and without Basalt fibers are shown in Figures 9 and 10. Field emission scanning electron microscope was used to visualize the concrete on microlevel. In Figures 9 and 10, the microstructure of HPFRC without mineral admixture (i.e., P-0) and with $3 \%$ Basalt fibers (PB-3) is captured. There is 

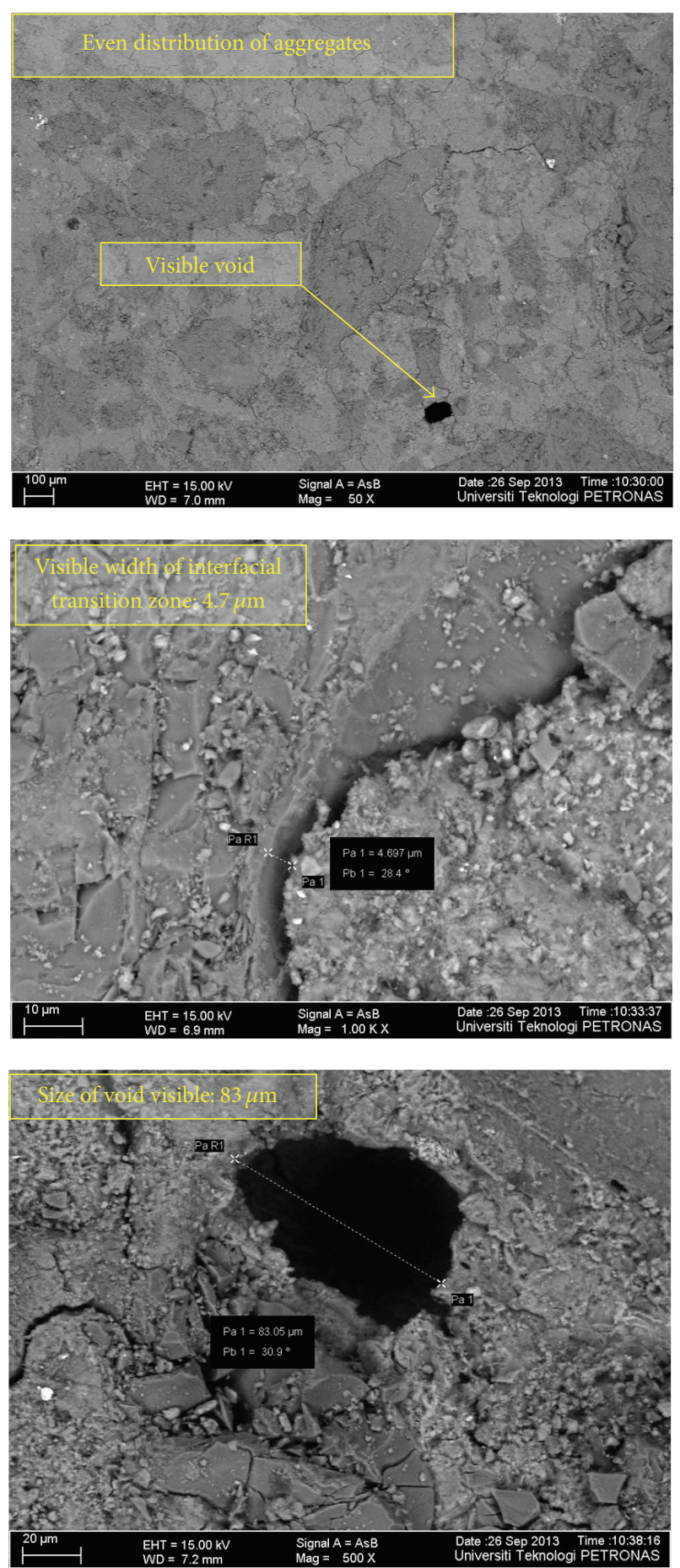

Figure 9: Microstructure of concrete mix "P-0."

an even particle size distribution in both the mix. However, there are some voids visible in HPFRC without Basalt fibers (P-0). This is due to the absence of mineral admixtures indicating that the concrete was not fully packed and some voids were left behind. This lacking was observed to be minimized with the Basalt fibers. The structure was more refined due to the addition of Basalt fibers and fibers were dispersed uniformly. The interfacial transition zone (ITZ) was improved due to the addition of Basalt fibers. The ITZ was
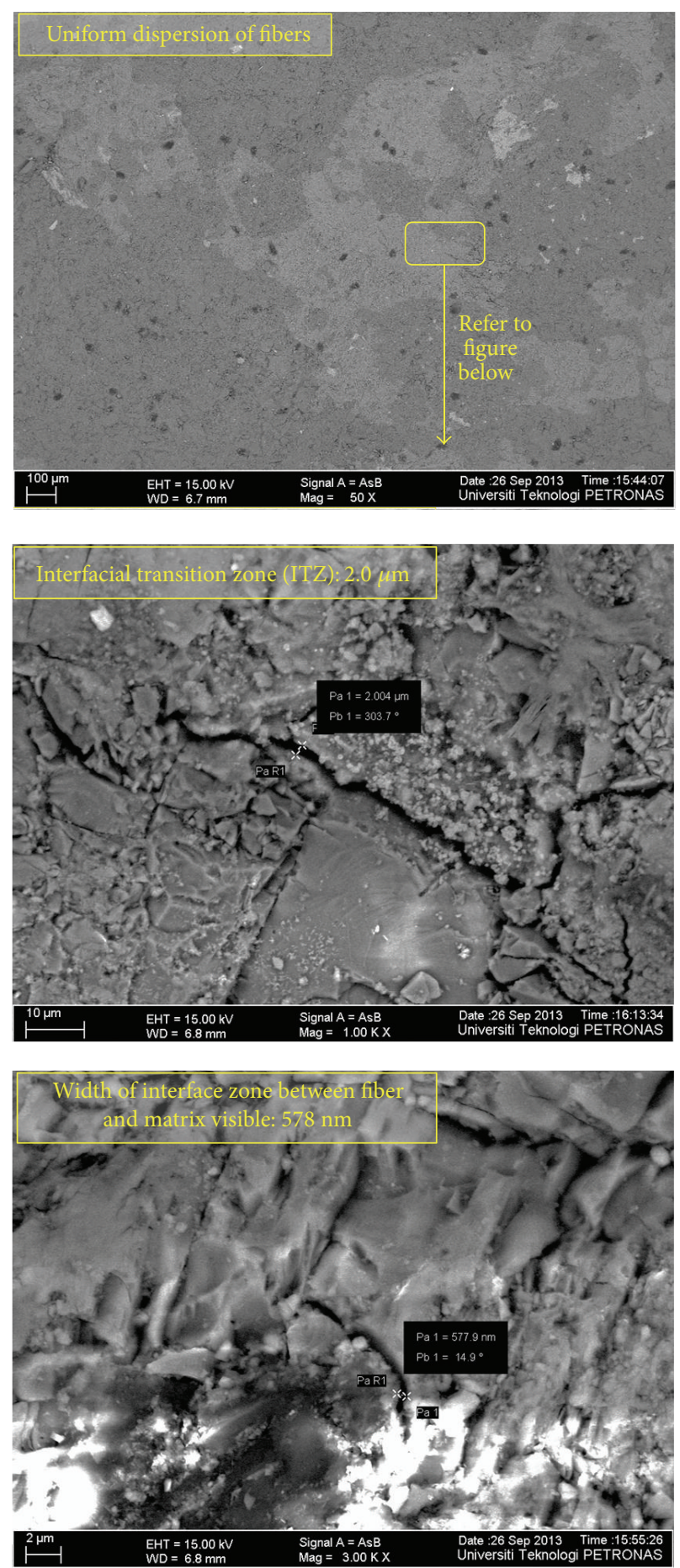

FIgURE 10: Microstructure of concrete mix “PB-3."

improved with the addition of Basalt fibers, which signifies the contribution of Basalt fibers in ITZ improvement. It may also infer that higher volume fraction of Basalt fibers does affect the microstructure of concrete positively.

In Figures 11 and 12, the microstructures of HPFRC with silica fume (S-0) and with 3\% Basalt fibers (SB-3) are shown. Cement replacement with the silica fume alone is very favorable in improving the ITZ of HPFRC as evidenced by comparing Figures 9 and 11. There are no voids visible in 

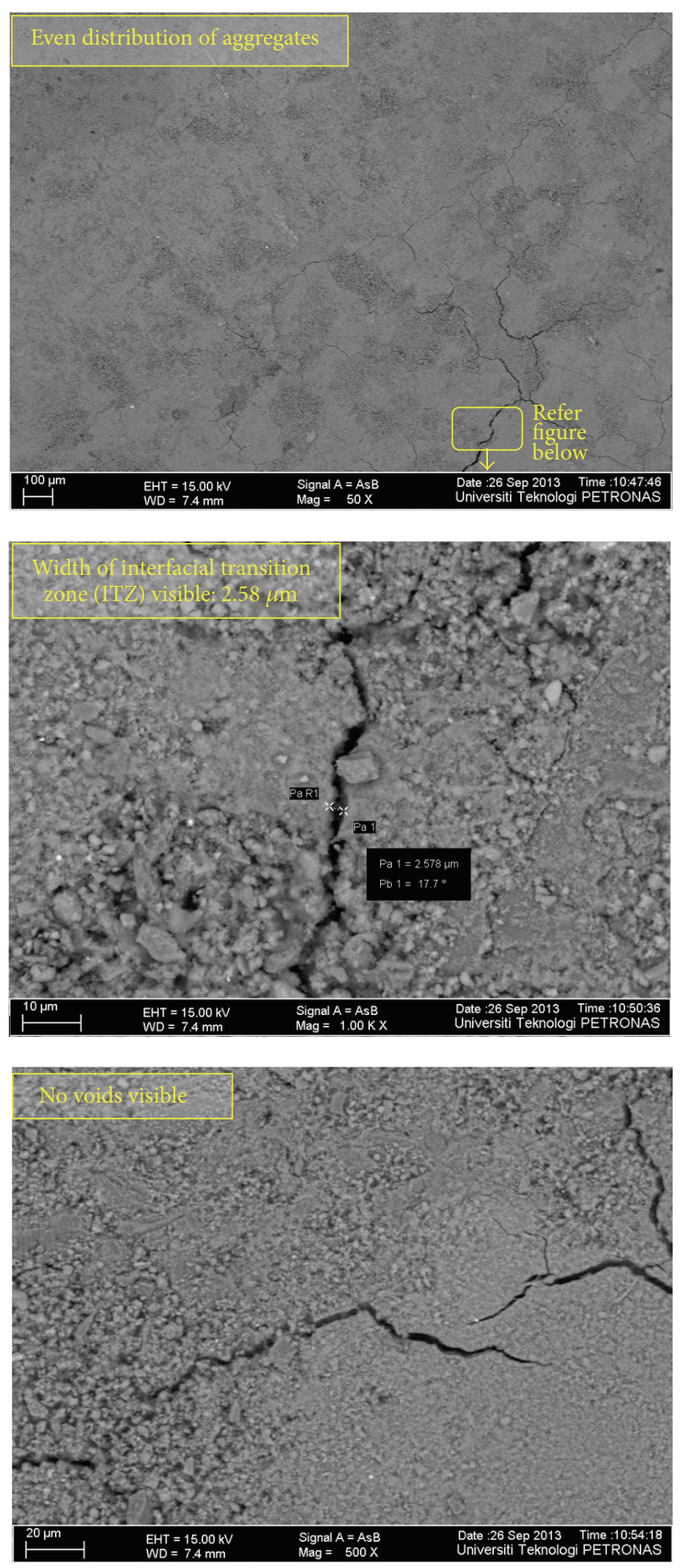

FIGURE 11: Microstructure of concrete mix "S-0."

the presence of silica fume. Though silica fume has better performance, the combination of Basalt fibers and silica fume (SB-3) is not good for microstructure characteristics of HPFRC. There are glimpses of unused portlandite $\mathrm{Ca}(\mathrm{OH})_{2}$ in the interface zone of fibers and matrix which suggest that secondary hydration has not been fully performed. This causes an increase in the interface zone between fibers and matrix as compared to HPFRC with Basalt (PB-3).
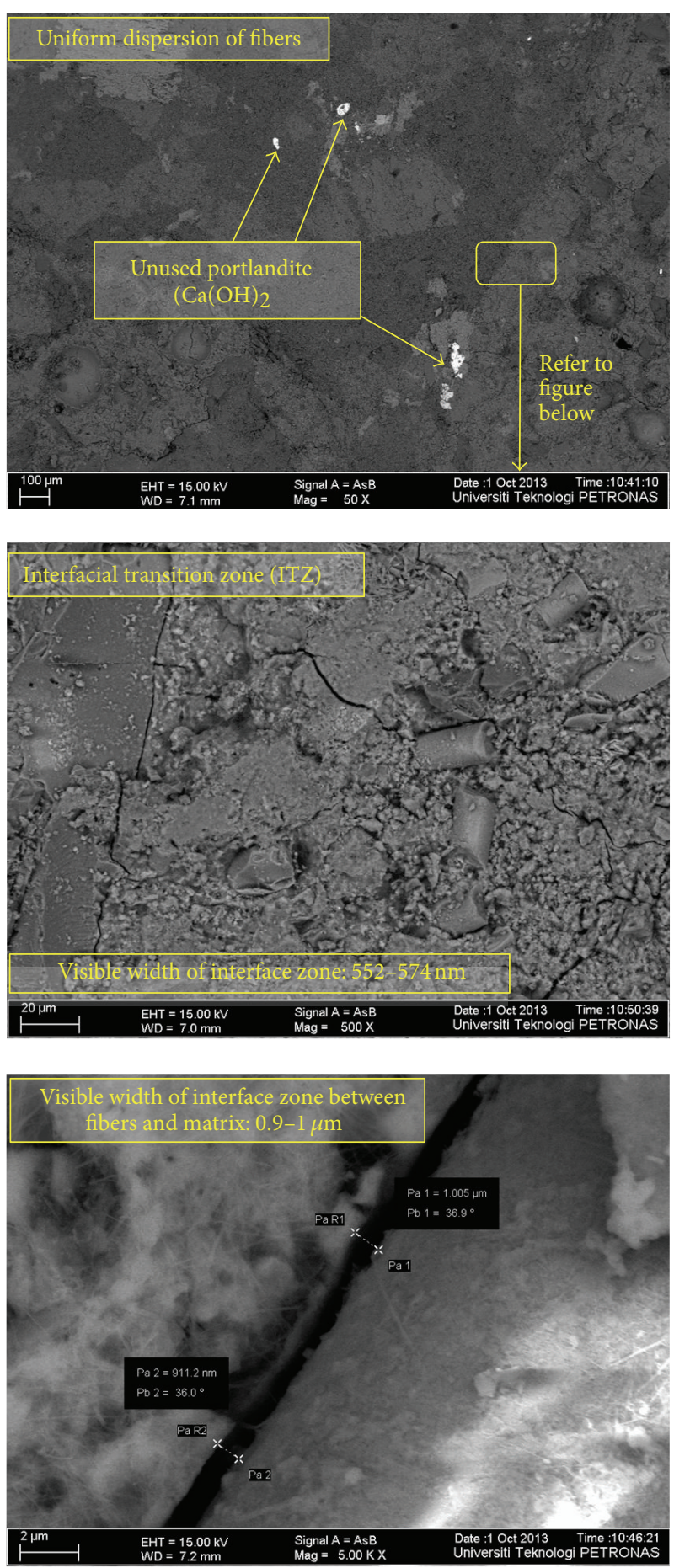

FIGURE 12: Microstructure of concrete mix “SB-3.”

In Figures 13 and 14, the microstructures of HPFRC with metakaolin (M-0) and with 3\% Basalt fibers (MB-3) are presented. The microstructure of HPFRC with metakaolin is the best among the all mixes studied in this research. There are no voids visible and ITZ is much improved as compared to $\mathrm{P}-0$ and $\mathrm{S}-0$. With Basalt fibers (MB-3) there is no visible ITZ and interface zone between fibers and matrix which signifies the improvement in microstructure and good mutual response of metakaolin and Basalt fibers. 

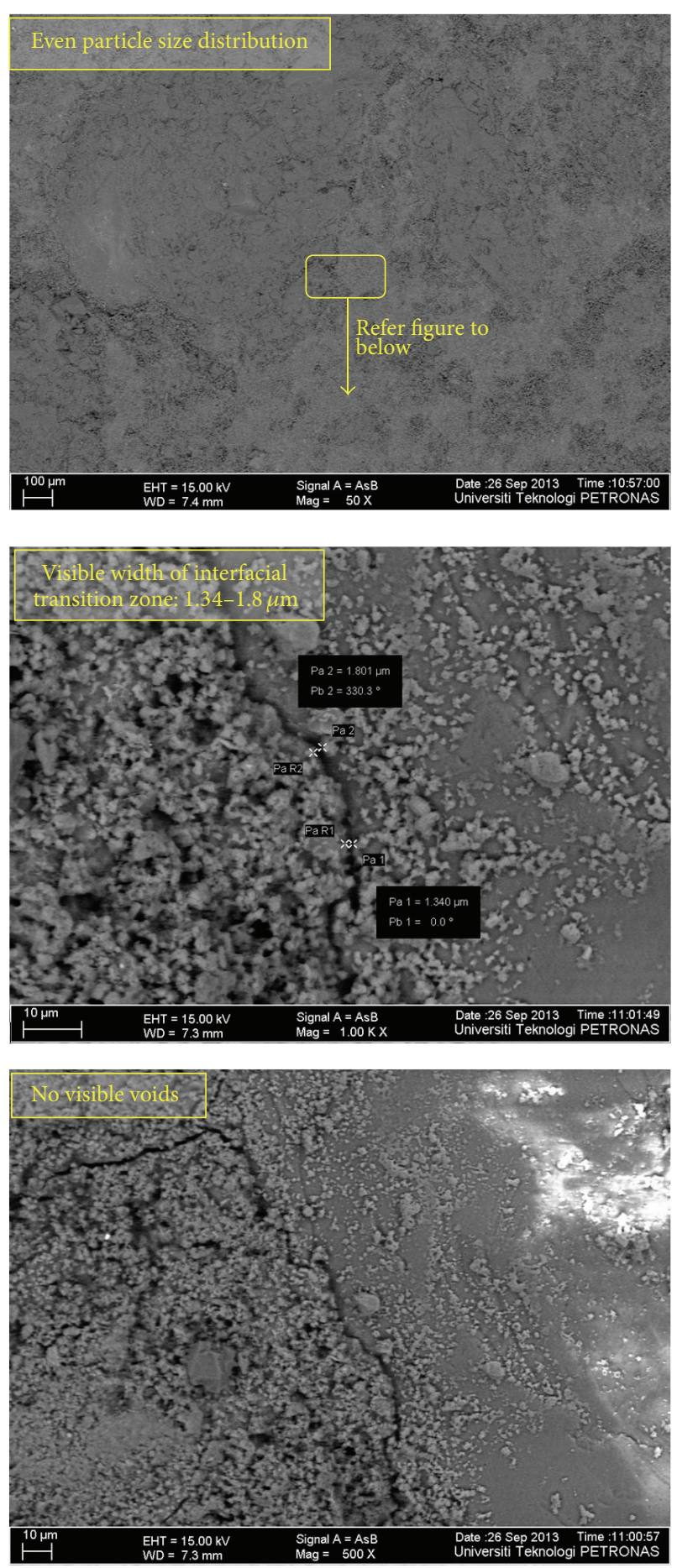

FIGURE 13: Microstructure of concrete mix "M-0."

\section{Conclusion}

The following conclusions are drawn from this study.

(i) The addition of silica fume and metakaolin to the concrete reduced the pore size as well as the $\mathrm{Ca}(\mathrm{OH})_{2}$ content in the ITZ of the aggregate and the paste as compared to the plain concrete. The pore size of
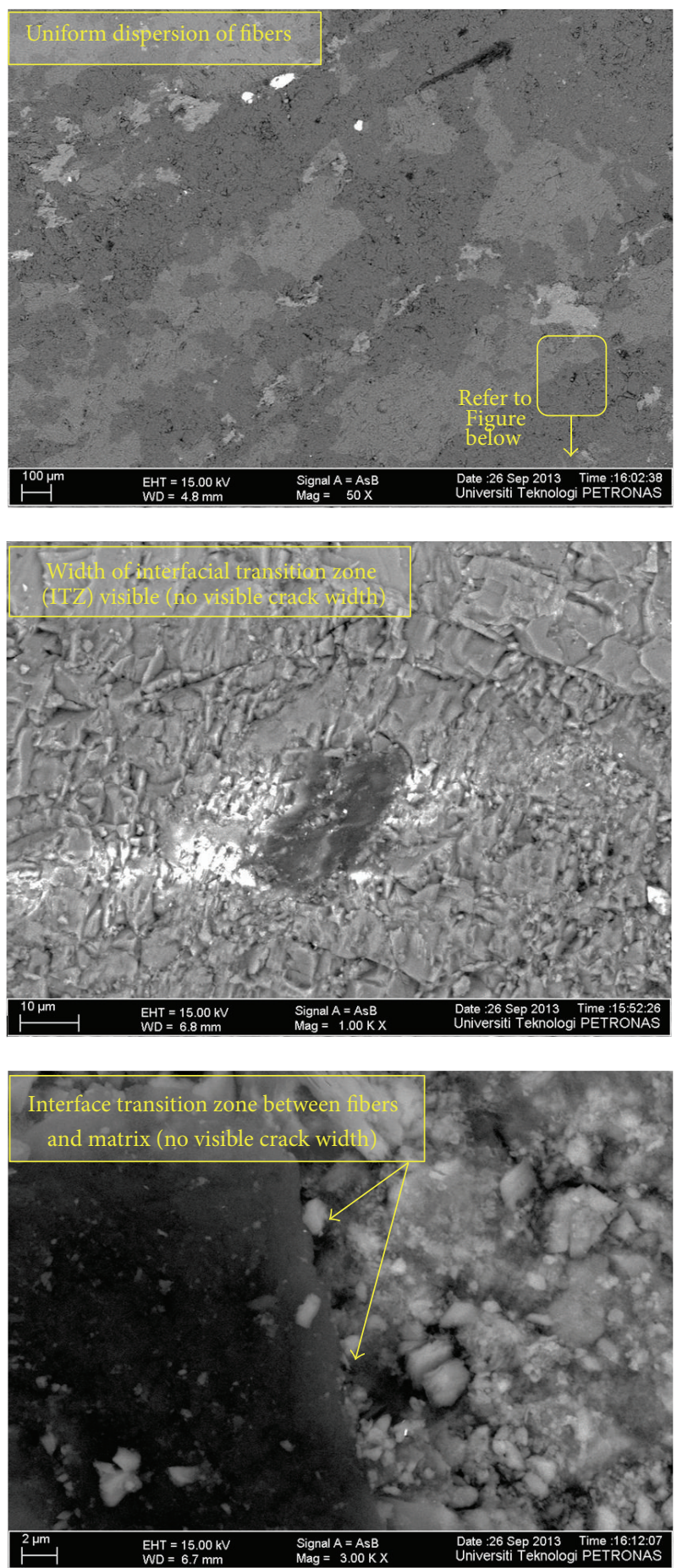

FIgURe 14: Microstructure of concrete mix "MB-3."

the metakaolin concrete was found to be lower than that of the silica fume concrete.

(ii) The use of silica fume (without fibers) increased the compressive strength (cube and cylinder), tensile splitting strength, and flexural strength as high as $15.37 \%$ and $28.88 \%$, and $4.81 \%$. In contrast, the addition of metakaolin increased the compressive, tensile splitting and the flexural strength of the concrete 
as high as $14.83 \%, 2.13 \%$, and $9.44 \%$, respectively. As compared to the silica fume concrete, there was a negligible variation in the compressive strength (both cube and cylinder) that was observed in the metakaolin concrete. The splitting tensile strength of the metakaolin concrete was found to be $21 \%$ lesser than the silica fume concrete, while the flexural strength of the metakaolin concrete was found to be $4.42 \%$ higher than the silica fume concrete.

(iii) The addition of Basalt fibers did not affect the compressive strength of the HPFRC. The variation in the average cube and cylinder strengths of HPFRC containing Basalt fibers was found to be in the range of $\pm 4 \%$ compared to the average compressive strength of the control specimens.

(iv) The addition of Basalt fibers improved the strain capacity of the HPFRC. The average increase in the compressive strains was found to be $4.76 \%, 9.99 \%$, and $12.20 \%$ when Basalt fibers were added as $1 \%, 2 \%$, and $3 \%$ by volume in the concrete mixes, respectively.

(v) The plot of stress-strain curves for all the mixes shows that the addition of fibers improves the postpeak behavior of the concrete. The slope of the descending branch of the control mix is steeper than those containing Basalt fibers. The reduction in the steepness is directly associated with the volume of the Basalt fibers; that is, the more volume of the fiber, the lesser the steepness of the descending branch of the curves.

(vi) For each of the three mixes of HPFRC, the tensile splitting strength was found to be significantly increased with the increasing volume of Basalt fibers. With respect to the control specimen (without fibers), the average increase in the tensile splitting strength of all mixes of concrete with $1 \%, 2 \%$, and $3 \%$ was found to be $1.64 \%, 5.27 \%$, and $23.95 \%$ higher. This shows that $3 \%$ Basalt fiber volume is the maximum fiber volume. Use of mineral admixtures (particularly silica fume) together with the basalt fibers significantly enhanced the tensile splitting characteristics of HPFRC in comparison to those concretes in which no mineral admixture or metakaolin was added.

(vii) Similar to the results of tensile splitting strength, the addition of Basalt fibers considerably increased the flexural strength of the HPFRC. The use of $1 \%, 2 \%$, and $3 \%$ Basalt fibers increased the flexural strength of the concrete as $18.15 \%, 36.12 \%$, and $27.17 \%$ higher than that of the concrete without fibers. Individually, the use of mineral admixtures, particularly metakaolin together with the Basalt fibers, significantly enhanced the flexural strength of HPFRC in comparison to the plain concrete in which no mineral admixture was added.

\section{Conflict of Interests}

There is no conflict of interest in this paper.

\section{References}

[1] S. U. Khan, M. F. Nuruddin, T. Ayub, and N. Shafiq, "Effects of different mineral admixtures on the properties of fresh concrete," The Scientific World Journal, vol. 2014, Article ID 986567, 11 pages, 2014.

[2] T. Ayub, S. U. Khan, and F. A. Memon, "Mechanical characteristics of hardened concrete with different mineral admixtures: a review," The Scientific World Journal, vol. 2014, Article ID 875082, 15 pages, 2014.

[3] T. Ayub, N. Shafiq, S. Khan, and M. Nuruddin, "Durability of concrete with different mineral admixtures: a review," International Journal of Civil, Architectural Science and Engineering, vol. 7, no. 8, pp. 199-210, 2013.

[4] J. J. Zeng, Z. H. Fan, and L. Chen, "Influence of metakaolin on strength and microstructure of steam-cured high-strength concrete," Advanced Materials Research, vol. 838, pp. 42-46, 2014.

[5] P. Rashiddadash, A. A. Ramezanianpour, and M. Mahdikhani, "Experimental investigation on flexural toughness of hybrid fiber reinforced concrete (HFRC) containing metakaolin and pumice," Construction and Building Materials, vol. 51, pp. 313320, 2014.

[6] E. Güneyisi, M. Gesoğlu, A. O. M. Akoi, and K. Mermerdaş, "Combined effect of steel fiber and metakaolin incorporation on mechanical properties of concrete," Composites Part B: Engineering, vol. 56, pp. 83-91, 2014.

[7] J. Han, Z. Shui, and G. Wang, "Research on the reactivity of Metakaolin with different grade," Sustainable Construction Materials, pp. 173-180, 2012.

[8] S. U. Khan, M. F. Nuruddin, N. Shafiq, and T. Ayub, "Calcined Kaolin as cement replacing material and its use in high strength concrete," submitted to Construction and Building Materials Journal.

[9] T. M. Borhan and C. G. Bailey, "Structural behaviour of basalt fibre reinforced glass concrete slabs," Materials and Structures, vol. 47, no. 1-2, pp. 77-87, 2014.

[10] T. M. Borhan and C. G. Bailey, "Modelling basalt fibre reinforced glass concrete slabs at ambient and elevated temperatures," Materials and Structures, vol. 47, no. 6, pp. 999-1009, 2014.

[11] Z. Kan and Y. Li, "Analysis on mechanical properties and durability of the chopped basalt fiber reinforced concrete," Advanced Materials Research, vol. 598, pp. 627-630, 2012.

[12] H. L. Wang and Y. H. Zhong, "Research status and proposals of basalt fiber reinforced concrete," Advanced Materials Research, vol. 834, pp. 730-737, 2014.

[13] V. Ramakrishnan, N. S. Tolmare, and V. Brik, Performance Evaluation of 3-D Basalt Fiber Reinforced Concrete \& Basalt Rod Reinforced Concrete, 1998.

[14] T. Ayub, N. Shafiq, M. F. Nuruddin, and S. U. Khan, "Mechanical properties of high-strength concrete reinforced with PVA and basalt fibres," in InCIEC 2013, pp. 567-575, Springer, 2014.

[15] L. J. Y. Y. Y. Meng and Z. Yan, "Experimental research on the mechanical behavior of chopped basalt fiber reinforced concrete," Industrial Construction, vol. 6, article 002, 2007.

[16] S. E. Artemenko, "Polymer composite materials made from carbon, basalt, and glass fibres. Structure and properties," Fibre Chemistry, vol. 35, no. 3, pp. 226-229, 2003.

[17] K. van de Velde, P. Kiekens, and L. van Langenhove, "Basalt fibres as reinforcement for composites," in Proceedings of 10th 
International Conference on Composites/Nano Engineering, pp. 20-26, University of New Orleans, New Orleans, Lo, USA, 2003.

[18] C. Jiang, K. Fan, F. Wu, and D. Chen, "Experimental study on the mechanical properties and microstructure of chopped basalt fibre reinforced concrete," Materials \& Design, vol. 58, pp. 187193, 2014.

[19] P. K. Mehta and P. J. Monteiro, Concrete: Microstructure, Properties, and Materials, 2006.

[20] E. Oztekin, S. Pul, and M. Husem, "Determination of rectangular stress block parameters for high performance concrete," Engineering Structures, vol. 25, no. 3, pp. 371-376, 2003.

[21] T. H. Wee, M. S. Chin, and M. A. Mansur, "Stress-strain relationship of high-strength concrete in compression," Journal of Materials in Civil Engineering, vol. 8, no. 2, pp. 70-76, 1996. 

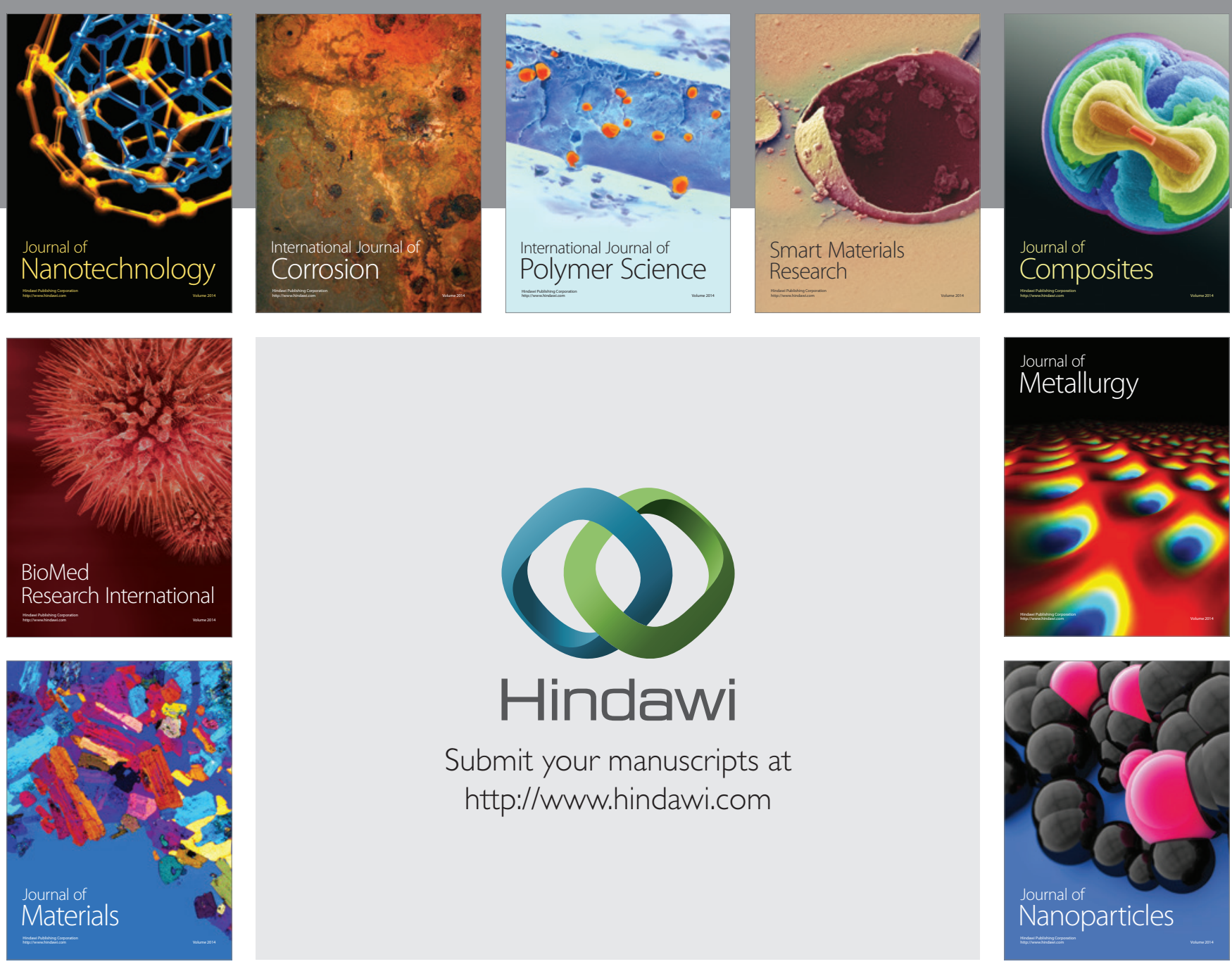

Submit your manuscripts at http://www.hindawi.com
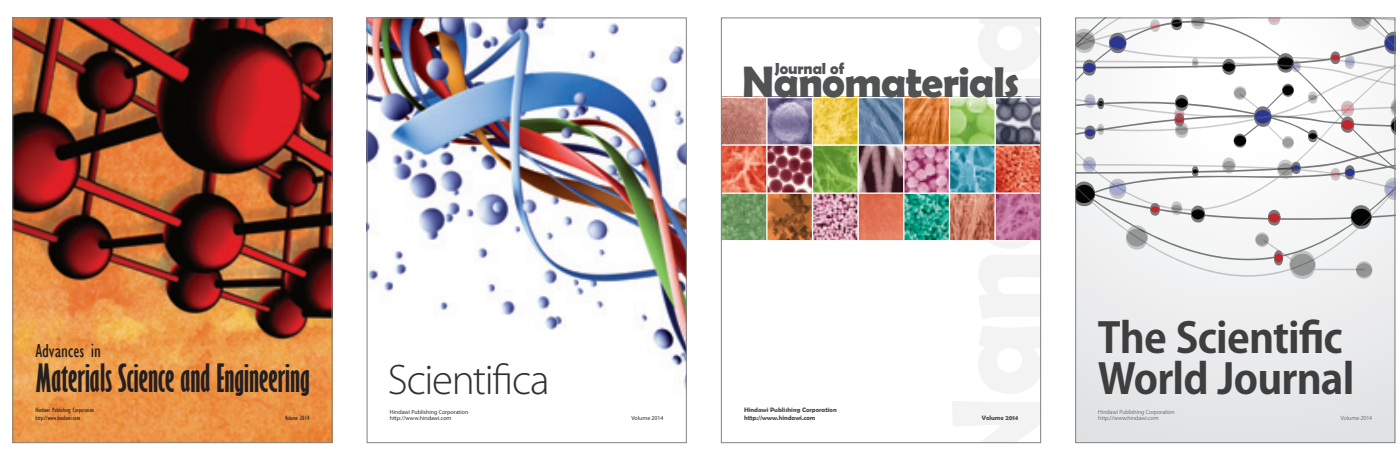

\section{The Scientific World Journal}
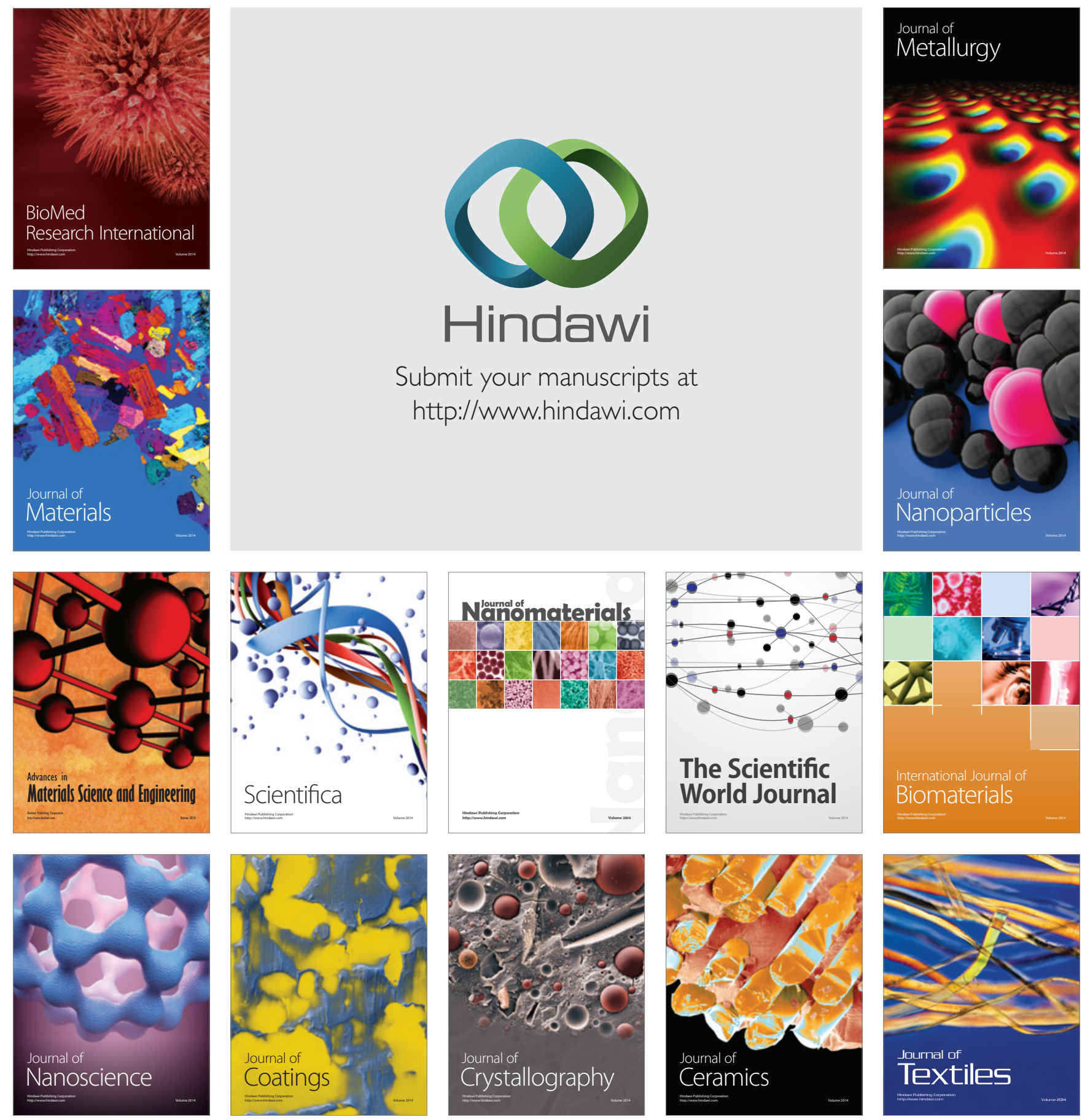